\title{
LA RECEPCIÓN CANÓNICA DE PALACIO COMO PROBLEMA DE LA MODERNIDAD Y LA HISTORIOGRAFÍA LITERARIA HISPANOAMERICANA
}

...Fino buceador de estados de alma, humorista, devoto de las modas literarias de su tiempo, Palacio orillaba el "disparate" con su ingénito lirismo [...].

Salvo en Jorge Icaza [...] los demás escritores ecuatorianos viven obsedidos por el sexo [...] no están exentos de ello Fernando Chávez ni el propio Pablo Palacio, tan cerebral y deshumanizado a veces (La vida del ahorcado, Un muerto a puntapiés) [sic], [...] ni el grupo de Guayaquil.

His clinical types - the syphilitic, the sex fiend, the murdererforeshadow some of the creations of the principal Ecuadorian group. In his surrealism and madness Palacio also foreshadows the new novel; indeed, he seems almost to be a character in one of Arlt's works.

Así de fragmentado y abierto es el marco en el cual se ha venido ubicando a Pablo Palacio y su obra. El primer comentario se encuentra en las confusas subdivisiones (novela de tendencia mixta, de aventuras, social, del inmigrante, etc.) que Luis Alberto Sánchez provee para lo que llama novelas de tendencia subjetiva, psicológica y modernista, en su conocido Proceso y contenido de la novela hispanoamericana (1953). El segundo comentario es de Sánchez también, en su Nueva historia de la literatura americana (1982), cuando ya convertido Palacio en sexópata, el crítico lo sitúa en la subsección "La novela social" de la rúbrica "Ojeada sobre las tendencias de postguerra (1916-1944)". El último comentario es de Kessel Schwartz, en el segundo volumen de $A$ New History of Spanish American Fiction (1971), en el cual Palacio, aparentemente todavía inhabilitado como novelista respetuoso de las convenciones del género que se le acusa de practicar, es parte de la "Public Service Literature, I'. 
Los comentarios anteriores muestran la lectura de un escritor muerto a cánones, en la dependencia genérica actual que admite toda lectura, comparación y abuso estético; todo sin mala intención. No obstante, no está de más recordar que, tal vez con mucha razón y clarividencia, Sánchez sitúa a Palacio, en 1953, junto a Clemente Palma, Macedonio, Arévalo Martínez, Borges, Bioy Casares y Xavier Villaurrutia. Palacio da para todo y todos, es la tarjeta de ciudadanía "boomista" de la narrativa ecuatoriana, es nuestro Kafka y sus precursores, nuestro proveedor de buenas y malas lecturas, nuestra fuente de orgullo, nuestro problema; y ahora el de otros.

Digo esto porque en este momento Palacio no necesita que se lo presente fuera del ámbito ecuatoriano. El comienzo de una recepción intercontinental inaudita para un narrador ecuatoriano se da en los años sesenta, cuando se publican las primeras obras completas, más o menos fiables, del autor. Desde entonces ha sido difícil encontrar un texto crítico sobre la narrativa hispanoamericana de vanguardia que no mencione cómo Palacio se aparta en su polifonía de los grandilocuentes discursos que caracterizan a los protagonistas de novelas tradicionales. En este autor, la trascendencia de todo tipo de discurso queda desvirtuada mediante la trivialización. Aleatorias o yuxtapuestas a esta práctica textual, la ironía y el humor (negro o grotesco) le precisan al lector el "intelectualismo" que la crítica ingenua ha querido inflar en Palacio.

Con mayor o menor fortuna, las lecturas que se han hecho de este autor han tratado las tematizaciones que menciono. Es por esto que para los propósitos de una valoración, para una contextualización de su obra, me parece superfluo esforzarse por encontrarle o rastrearle la modernidad, lo cual sería - si se termina comparándolo con un Joyce (como se ha hecho en la crítica ecuatoriana) o con un Kafka o un Walser (pienso en que el "Teniente" de Débora es el diarista en Jakob von Gunten (Ein Tagebuch) [1908])caer en una imprecisa dependencia en modelos europeos. Por esto vuelvo al "problema" que anuncio en mi título.

Lo que me interesa examinar aquí es la manera como Pablo Palacio y su obra han llegado al punto en que se encuentran, y hasta dónde se puede depurar críticamente una obra genéricamente indeterminada, magra en términos de lo que pudo producir el autor, pero sobre todo valorizada contradictoriamente. Palacio da cuerpo a las posibilidades de emplear críticamente frases populares o popularizadas como "en la casa del ciego el tuerto es rey", o "nadie es profeta en su tierra". Creo que en este sentido el autor ecuatoriano no es nada diferente de muchos narradores que entre 
los años 1923 y 1938 producen obras verdaderamente precursoras, que por razones expuestas por muchos críticos o que veremos, han quedado marginadas para sólo ser rescatadas en nuestros días.

Un hombre muerto a puntapiés y Débora, ambas de 1927, Vida del ahorcado (novela subjetiva) [1932], unos relatos publicados entre 1921 y 1930 (algunos de los cuales resultaron ser anticipos de sus novelas), traducciones, ensayos semi-filosóficos, uno que otro poema, y la novela inédita Ojeras de virgen (1926) componen las verdaderas "obras completas" de este autor". Éstas bastaron para que la historiografía literaria ecuatoriana cambiara, paulatinamente; y para que, por ende, la lectura que de ellas (obra e historiografía literaria) se haría experimentara una relación de causa y efecto que llevaría a la consideración de cambios en la noción de la más amplia historiografía literaria hispanoamericana, o a poner en perspectiva a otros "raros" o adelantados de ésta.

El problema es extenso, ya que se está lidiando, sólo para comenzar, con cuatro situaciones: a) una recepción irresoluta; b) una historiografía (de aquí en adelante, entiéndase que ésta es literaria) inflexible; c) una ofuscación genérica; d) una modernidad incierta. Por supuesto, estas divisiones nunca serán contundentes, ni tan tajantes como la crítica que busca en Palacio lo que no hay. No obstante, no creo que sea exagerado hacer una lectura bajtiniana, digamos, de la obra del autor. Por esto mismo, estos problemas no tienen límites, establecen diálogos, a veces sin ayudarse. Porque en Palacio el diálogo es una manera de recuperar enclaves, una manera de recuperar la lectura y de permitirle al lector llegar a metalecturas por medio de las cuales se revela el complejo mundo que Palacio ha recuperado con su obra.

Si vamos en orden, la recepción irresoluta se debería examinar desde su componente más "objetivo" al que - repito, con buena intención - se deja cegar por un patriotismo que en su versión crítica peca de impresionista. Vamos entonces de lo general a lo particular, de lo internacional a lo nacional. En el segundo tomo ("Época contemporánea") de la más reciente edición (1974) de su conocida Historia de la literatura hispanoamericana, Enrique Anderson Imbert califica a Débora de novela "de tono sentimental". Para él, Vida de un ahorcado [sic], es "exacerbada, angustiada",

1 Humberto Robles, "Pablo Palacio: el anhelo insatisfecho", Cultura, Quito, 1984, núm. 20,63-77, provee la cronología más fiable de las obras del autor, a pesar de no dar detalles sobre el trabajo de recopilación y notas que hizo Jorge Enrique Adoum para la edición de 1964 de las obras completas. 
a pesar de admitir fugazmente (y por extensión, de manera injusta) que los monólogos interiores que practicaba Palacio "serán ejercicios impuestos por los maestros de escuela", sin que se aclare la ironía sobre cuáles maestros o qué escuelas.

José Juan Arrom, en la segunda edición de su condensación de las letras hispanoamericanas, da todo indicio y justificación de que el lector encontrará el nombre de Palacio. Cuando habla de las características de la generación de 1924, a la cual pertenecería Palacio si se aceptan las premisas de Arrom, arguye que la obsesión por los "ismos" se debe al desasosiego de la juventud de entonces ante el desquiciado mundo de la posguerra. Para este crítico el irracionalismo, el hermetismo y la escritura automática (que Palacio textualizaba y privilegiaba con gran valentía en el cerrado contexto nacional en que se hallaba), son simplemente "un común anhelo de afirmación individual, una búsqueda de certezas en un clima de incertidumbres, un patético deseo de transitar todos los rumbos con la esperanza de hallar el camino de la propia salvación. Y esa es la línea profunda, sajada en carne viva, que marca el perfil de la promoción vanguardista'"2.

Créase lo que se crea sobre esta postura ante el vanguardismo en la prosa, la verdad es que la lectura de Palacio le revela a Arrom mucho de lo que atribuye a sus coetáneos. Lo que pasa es que ni siquiera menciona al ecuatoriano. Tampoco lo hace Fernando Alegría en la versión levemente corregida y aumentada (1986) de su ahora Nueva historia de la novela hispanoamericana. La misma ausencia se nota en la versión de 1980 de la bien conceptualizada historia del mismo género que hace Cedomil Goić. Por último, textos anteriores sobre la novela, como el de Gertel (1970) o el de Brushwood (1975, la versión en español de 1982 tampoco llena la laguna), no parecen saber de la existencia de Palacio, a pesar de nombrar a autores de similar literariedad que, con muchas lecturas posteriores, resultan ser estéticamente análogos a aquél en su producción.

Pero temo que debo parar aquí, ya que el registro no terminaría, o se convertiría en catálogo innecesario. No obstante, debo hacer la salvedad de que la recepción fuera del Ecuador no ha sido totalmente un simple pecado de omisión. Una conocida crítica brasileña encuentra en la obra cáustica y contestataria de Palacio grandes coincidencias con la postura estética del modernista brasileño Oswald de Andrade. Dice ella: "Como em quasse todos os artis-

2 JOSÉ JUAN ARROM, Esquema generacional de las letras hispanoamericanas: ensayo de un método, Instituto Caro y Cuervo, Bogotá, 1977, p. 207. 
tas sul-americanos, há, em Pablo Palacio, um conflito entre seus ideais e os da sociedade em que viveu, um protesto contra o que considerava menosprezo da beleza, constituindo-se, como sua obra, em consciência crítica. Mas não existe nela uma desctruição do passado: se assim fosse, seria uma radicalização superficial. Essa inquietação própria da vanguarda da década dos vinte é o desencadeamento crítico de novas estruturas"'3.

Esta afirmación toma lo que es predecible para el lector constante de Palacio y su crítica y le da una concisión que adquiere otra dimensión sólo en el segundo lustro de esta década. Únicamente con la lectura de los "nuevos" se llega a apreciar a sus antecesores. Se invierte la progresión: los más recientes se convierten en parangones, los mayores en novelistas ejemplares. Y se plantea, tal vez pleonásticamente, por enésima vez, la compleja relación ficción-realidad, se privilegia el formalismo:

Tales incursiones psíquicas y expresiva, de sesgo metafísico, podrían haber quedado como ocurrencias pasajeras o desviaciones enfermizas del autor, si la historia de la expresión literaria no diera cuenta de su permanencia y afirmación en ciertas líneas de la literatura contemporánea. Si en las tres primeras décadas del siglo observamos tales características dando un aire común a los artistas del Viejo y el Nuevo Mundo, acaso podríamos afirmar que a partir de 1930 es en América Latina donde se despliega, ya con nuevos matices, la aventura vanguardista-surrealista ${ }^{4}$.

Aunque la aventura pudiera regresar o hallar sus raíces en la Lucía Jerez (1885) de José Martí - si el crítico se ciñe al facilismo interpretativo que ofrece la dicotomía ficción-realidad-, las líneas generales de la afirmación citada cubren el problema que Palacio le ocasiona al intérprete del tipo de narrativa aducida.

Lo anterior es sólo una parte de la recepción irresoluta de Palacio, es en verdad una internacionalización que se está dando y que, de una manera u otra, depende de la recepción que el autor ha tenido en su propio país. Pero notemos que esa dependencia no es algo fijo ni progresivo o revisionista. Precisamente al principio, la recepción crítica ecuatoriana, a pesar de señalar el valor de novedad del autor, no logró superar su reticencia ante lo que

3 Bella JozeF, "Pablo Palacio, um renovador" en $O$ jogo mágico, Livraria Jose Olympio, Rio de Janeiro, 1980, p. 139.

${ }^{4}$ GRACIELA MATURO, "Apuntes sobre la transformación de la conciencia en la vanguardia hispanoamericana"', en Fernando Burgos (ed.), Prosa hispánica de vanguardia, Orígenes, Madrid, 1986, p. 49. 
le mostraba las deficiencias de la narrativa anterior que ella misma (la crítica) había propulsado con gran entusiasmo. Es decir, el compromiso con Palacio tenía que ser algo muy calculado, con pátina normativista.

En 1948 Ángel F. Rojas publica la que es hasta hoy la historia más crítica (dentro y fuera del Ecuador) de la novela ecuatoriana. Lo que es evidente en las trece "conclusiones y confirmaciones" con que finaliza su obra es su sentido de frustración ante la recepción de las novelas nacionales. Para poner en perspectiva la recepción fuera del Ecuador que he resumido anteriormente, leamos parte de la novena conclusión/confirmación de Rojas:

La crítica literaria extranjera es la que toma a su cargo, antes que la nacional, la exaltación del valor de los nuevos novelistas ecuatorianos. Su fama, en vez de irradiar desde el centro donde lanzaran sus producciones, ha venido desde afuera [...]. La novela ecuatoriana contemporánea, según la crítica foránea lo anota, constituye una de las realizaciones más interesantes de América y, como conjunto, apenas admite parangón ${ }^{5}$.

Ésta, tal vez la más crítica de las conclusiones/confirmaciones generalmente optimistas de Rojas, se da -cronológica y naturalmente - antes de que Aguilera Malta llegue al apogeo de su tipo de realismo mágico, y consecuente y muy merecida canonicidad; antes de que despegue Alfredo Pareja Díez-Canseco y que entre en escena Pedro Jorge Vera. Ni hablar de Jorge Enrique Adoum, quien (como veremos), ya como decano de la novela ecuatoriana inmediatamente moderna, es el novelista que examinará la obra de Palacio con mayor objetividad y asimilación crítica.

El optimismo de Rojas, a pesar de los breves e inteligentes comentarios que hace sobre Palacio (especialmente sobre el espacio político-social que representaba en su obra), no llega a tocarlo, porque cree que "produjo una literatura difícil, demasiado intelectualizada. Su ironía magistral le hacía temible, pero lo aislaba en un reducto. La postura que adoptaba frente a los personajes a los cuales hacía comparecer a escena nos está dada por su manera de presentarlos a los ojos del lector [...]"'6. Irónicamente, las dificultades que intuye Rojas son lo que los lectores y críticos actua-

${ }^{5}$ Ángel F. RoJAS, La novela ecuatoriana, F.C.E., México, 1948, p. 218. Entiendo que se ha publicado una edición ecuatoriana de este clásico en 1977 , pero no he podido consultarla para verificar cambios posibles sobre la evaluación de Palacio.

${ }^{6}$ Ibid., p. 179. 
les juzgan como estéticamente válido. ¿No son los sesudos acontecimientos fragmentados, el discurso velado y contraditorio, el continuo desmentir humorístico, semióticas afines y la función del lector - características de Palacio si las hay - gran parte de lo que está determinando lo que se considera moderno hoy?

Se podría decir que la evaluación de Rojas es típica de su época. Lo grave es que en el Ecuador, con raras excepciones, no se ha logrado superar lo que, después de todo, es una crítica aguda y clarividente; ya que Rojas, a muy pocos años de la muerte de Palacio, logra una distancia que críticos posteriores raramente emularán. Diez años después de publicado el libro de Rojas, por ejemplo, el crítico Edmundo Ribadeneira M. acusa a nuestro autor, de una manera poco velada, de ser anti-ecuatoriano. Lo interesante es que Ribadeneira se ve obligado a admitir el valor "universal" y la modernidad de Palacio. Pero lo disminuye y se contradice, diciendo que su literatura es "propia de un cerebro que excluye el enfoque progresivo y que de ninguna manera hace bien a la patria" 7 . Es un patriotismo en el que se detecta una patente diferencia ideológica.

Para Ribadeneira la narrativa de Palacio es negativa, dañina para una interpretación de "lo ecuatoriano", porque es la obra de un autor que sufre de una conciencia que, entre otras cosas, es falsa: " propugna, por ejemplo, un socialismo ecuatoriano, pero se da en escribir cosas desconcertantes, cuentos y novelas sombríos con personajes que difícilmente podrían llamarse ecuatorianos"'. Aparte de anotar que el crítico nunca explica las fuentes verídicas de su falacia biográfica, le dejo al lector el metamensaje de lo citado. Para Ribadeneira, Palacio y su obra son amargos $\mathrm{e}$ inhumanos, indignos aunque inteligentes; y concluye que si en su época no se supo prevenirla y analizarla como un producto ajeno al Ecuador, es hora de ubicarla donde pertenece [¿?]. Pero más reveladora para la lectura que propongo es su aserción de que el lector está ante un escritor inconsecuente con su posición política, que "no hace sino trasplantar a nuestra literatura ideas y conceptos que no coinciden con nuestra verdad nacional y la obligación de ponerse a tono con las necesidades de la patria y la humanidad"'.

Este llamado a la militancia ciega y al hermetismo, que yo sepa,

7 EDMUNDO RibAdENEIRA M., La moderna novela ecuatoriana, Casa de la Cultura Ecuatoriana, Quito, 1958, p. 159.

${ }^{8}$ Ibid., pp. 157-158.

${ }^{9}$ Ibid., p. 158. 
no ha sido criticado o contestado. Tal vez sea una muestra de una actitud posterior más abierta y crítica el que se incluyan las líneas que Ribadeneira le dedica a Palacio en una de las más recientes compilaciones sobre éste ${ }^{10}$. No obstante, la recepción ecuatoriana del autor después de que Ribadeneira lo acusa de ser, en el mejor de los casos, apátrida y extraño, no es mucho mejor. Por ejemplo, en el ideológicamente transparente (como muestra, véanse los agrios comentarios personales sobre la posición política de Jorge Icaza) Diccionario de la literatura latinoamericana: Ecuador (1962), que Isaac J. Barrera y Alejandro Carrión prepararon para la O.E.A. en Washington, Palacio y su obra brillan por su ausencia.

Sólo a fines de los sesenta se comienza a recuperar la trascendencia narratológica de Pablo Palacio, quien en una novela "anticapitalista", arltiana, hiperbólica (se subasta el Chimborazo) y visionaria como Vida del ahorcado, hace que el "camarada" Andrés, quien a veces es el narrador, le diga a Ana: "[...] no te ilusiones. El campo sólo era tierra grande, con viento. Nosotros, americanos, no hemos podido conocerlo ni amarlo. ¿Recuerdas cómo era de noche esa cosa grande, callada, oscura e impenetrable? Tengo miedo del campo; el límite, el límite es lo mío" (p. 130) ${ }^{11}$. Digo recuperar porque este tipo de lirismo, combinado con elementos supuestamente autobiográficos y eufemistas, sólo se concretiza con una lectura abierta.

Así es como se comienza a emitir juicios que críticos posteriores retomarán sin darles mayores matices. Uno de los principales es que "Pablo Palacio no es un escritor realista en el sentido riguroso del término. Cierto que su literatura apunta a desprestigiar la realidad, como él mismo lo asegura; pero, cargada de obsesiones personales, imágenes subjetivas y reflejos de traumas psíquicos, no posee la transparente intención social que puede hallarse en las novelas de Icaza o del grupo de Guayaquil. Mas no por ello es menos valiosa[...]" ${ }^{\prime 12}$. Bastante exacta, esta afirmación es

${ }^{10}$ Con el mismo título significativo del original de 1958, "Presencia y ausencia de Pablo Palacio", en ALEJANDRO CARRIÓN et al., Cinco estudios y dieciséis notas sobre Pablo Palacio, Casa de la Cultura Ecuatoriana, Guayaquil, 1976, pp. 79-82. Hasta la fecha de su publicación ésta es la colección más representativa de la crítica ecuatoriana sobre Palacio. Entiendo que está por salir la Valoración múltiple de Pablo Palacio, publicada por Casa de las Américas (compilador Miguel Donoso Pareja) donde se ofrece una dimensión internacional.

${ }^{11}$ Citaré por la siguiente edición, poniendo entre paréntesis el número de la página: PABLo PALACiO, Obras completas, Casa de la Cultura Ecuatoriana, Guayaquil, 1976.

${ }^{12}$ Agustín Cueva, La literatura ecuatoriana, C.E.A.L., Buenos Aires, 1968 , p. 54. 
una manera sutil de acercarse al cúmulo de consideraciones y sensaciones que los personajes de Palacio le van ofreciendo al lector.

Pero la recepción de Palacio en su país no posee ningún foco, monopolio o hegemonía. Y esta falta de patrón, especialmente cuando se está leyendo a un autor que inevitablemente es mencionado como la causa de la inserción de la narrativa ecuatoriana en cierto tipo de canon, es reveladora de un problema cuyas vertientes son ideológicas, estéticas, y sobre todo, críticas; ya que es este último campo el que va a difundir lecturas como la que presento aquí. En este sentido, Palacio sigue malentendido en su país. Si se lo aprecia es por ser sui generis, si se lo rechaza es por su "demencia". Esta ambivalencia nunca lleva a una verdadera interpretación crítica; lo que para mí revela es una falta de distancia en la lectura.

Galo René Pérez, por ejemplo, lee en Palacio un autor solitario, lo que para él no quiere decir que el narrador lojano sea el mayor de la narrativa ecuatoriana ni el menos imitable. Lo que sí precisa Pérez es que en Palacio:

Quiere hallar un personaje de rasgos definidos, de rostro que no se esfume, y únicamente siente el soplo de un fantasma que el autor se lo escamotea cuando intenta aprehenderlo. Quiere descubrir una doctrina, una tesis clara y coherente, un pensamiento central, o siquiera un sentimiento más o menos constante, y no da con ellos. Quiere advertir siquiera la unidad externa, la usual, de la ordenación de los capítulos, o la relación lógica de sus títulos, y aun este empeño es vano ${ }^{13}$.

Si bien es cierto que Palacio comparte con la mayoría de los narradores hispanoamericanos y extranjeros de su época la textualización de una búsqueda bastante compleja, no es cierto - según la lectura correctiva que propongo aquí- que esté tratando de llegar a un centro, al logos, peor aún, a los convencionalismos que la tradición novelística de su época le presentaba. Pérez no lee que lo que está diciendo Palacio es que en el mundo que lo rodeaba, mundo que inmediatamente será nuestro, el logos y el centro no existen, y si un lector cree que se dan, no sirven para mucho.

Pero no se debe creer que éste es el tipo de lectura que va a predominar en años recientes, pues tampoco quiero convertir la mía en algo menos que actitud crítica. Lo que quiero señalar, sobre

13 Pensamiento y literatura del Ecuador (critica y antología), Casa de la Cultura Ecuatoriana, Quito, 1972, pp. 410-411. 
todo, es la inconsistencia en la lectura específicamente crítica de Palacio, ya que por cierto no se puede pretender que la lectura general de este autor sea homogénea. La lectura que me parece más fiable para autores como Palacio es la que toma en cuenta todas las fuentes de la literariedad de un autor. Para mí, es Jorge Enrique Adoum quien inicia este tipo de acercamiento con gran rectitud y la seriedad de distancia que mencionaba anteriormente. Adoum nota que es inevitable que la ideología del lector, la de los personajes, narradores, signos y la logística de la publicación se crucen. Es ésta la noción de que los objetos narrativos, en sí desposeídos de significado, lo adquieren por medio de su rol en el proceso de producción de un texto. Éste tiene que ver con los códigos y estrategias que están en función cuando el lector lee. Es decir, al leer debilitamos los lazos que nos unen estrictamente al mundo social y al mundo de acción para ajustarnos a lo ideológico ${ }^{14}$.

Adoum, entonces, enfoca el desarrollo de las letras ecuatorianas como una progresión de desconocimiento que se desborda desde lo nacional hacia lo internacional. No es ignorancia, se trata sobre todo de no haber constatado la relación estrecha entre el desarrollo de los intereses de clase y la representación de éstas. Según Adoum, sólo después de la formación del Partido Socialista ecuatoriano (Palacio tenía entonces unos veinte años, y pronto pasó a coadyuvar en él y a depurar sus bases ideológicas, fundando el semanario Cartel) se adquiere en el país conciencia de la realidad de otras clases y su posible inclusión en la narrativa. Esto llevó a una representación bastante realista (en sentido estricto) de las clases sociales, sobre todo de la clase media concentrada en las ciudades.

Es entonces cuando Adoum describe claramente lo que la crí-

${ }^{14}$ Sigo las líneas generales de la excelente revisión del efecto de la ideología en las estructuras de la novela, propuestas en LENNARD J. DAVIS, Resisting Novels: Ideology and Fiction, Methuen, New York-London, 1987. A esto añado, como se notará en mis argumentos, la estética de la recepción, como metodología más idónea para una obra como la de Palacio. Para aplicaciones específicas véanse: DIANA SORENSEN GOODRICH, The Reader and the Text: Interpretative Strategies for Latin American Literatures, J. Benjamins, Amsterdam, 1986; LISA BLOCK DE BEHAR, La retórica del silencio, Siglo XXI, México, 1984; y WILFRIDO H. CORRAL, Lector, género y sociedad en Monterroso, Universidad Veracruzana, Xalapa, 1985. De los muchos estudios panorámicos véanse sobre todo Susan R. Suleiman e Inge CROSMAN (eds.), The Reader in the Text, Princeton University Press, Princeton, 1980; ROBERT C. HolUB, Reception Theory, Methuen, New York, 1984, y ROGER Chartier (ed.), Pratiques de la lecture, Rivages, Marseille-Paris, 1985. 
tica anterior no podía admitir por completo, y es que la clase media ecuatoriana, como la de otros países " [...] sufre de una inautenticidad o de una indecisión entre la fidelidad a un ideal o a una ideología y la tendencia (yo creo que innata en esta clase) hacia la justicia y la necesidad aparente o cobarde de apartarse de ella [...]. Pablo Palacio logró ver con gran claridad esta indecisión de la clase media, este vivir crucificado entre una tendencia idealista y una realidad sórdida, esta indecisión para tomar una actitud"'15.

¿Pero qué pasa con la lectura de la narrativa ecuatoriana posterior, en la cual, como se ha visto, se espera encontrar atisbos de Palacio? En este punto el lector interesado deberá ubicarse en los últimos diez años de la crítica sobre el autor. En términos de la narrativa hispanoamericana, estamos saliendo del "boom", sin ningún indicio de qué es lo que seguirá (si se lo acepta como demarcación literaria). En 1977, se publican los esbozos de una encuesta/formulario que propone esclarecer la búsqueda generacional de las letras ecuatorianas. Entre las preguntas a que se someten por lo menos cincuenta autores y críticos está, con variantes, la de "¿Qué narradores, a partir del Treinta, no deben faltar en una historia de la narrativa ecuatoriana?"

Las respuestas, previsiblemente, incluyen la mención de Palacio; los elogios abunda, pero el ambiguo compromiso con su estética persiste. Lo que sí es verdaderamente revelador es que se trate de justificar la pertenencia de Palacio al "boom". El problema cronológico es en cierto sentido superable, si se considera a narradores como Marechal, Onetti y otros. No lo es tanto esa especie de predicción mágica que propone una consistencia estética en la producción de un autor. Sin embargo, en la "Discusión" que sigue a las opiniones mencionadas, la intervención de María Eugenia González apunta a otras dimensiones del "problema Palacio":

Ninguno de nuestros escritores, ni los de la llamada "Generación del treinta", ni de la actual, se encuentran en el "boom" latinoamericano. La razón es una sola: falta de publicidad.

La mayoría de los compañeros de esta discusión han mencionado a Pablo Palacio como un candidato al "boom" si viviese todavía. Pero yo me pregunto: si Palacio estuviera vivo ¿le habríamos dado una oportunidad para que su nombre trascienda dentro y fuera de los linderos ecuatorianos? Positivamente creo que no. Un público

${ }^{15}$ JORGE ENRIQUe AdOUM, "Las clases sociales en las letras contemporáneas de Ecuador", en Jorge Enrique Adoum et al., Panorama de la actual literatura latinoamericana, Casa de las Américas, La Habana, 1969, pp. 163-164. 
que no sabe leer, que compra libros únicamente por llenar un estante bonito, que busca satisfacer sus anhelos viviendo una telenovela o leyendo una novela rosa, no habría comprendido a Palacioo ${ }^{16}$.

Lo que no considera González, 'aparte de hacer precisiones que en verdad se pueden aplicar a otros grupos de lectores hispanoamericanos, es que la crítica (que trata de mantenerse al tanto con sus practicantes en otros países) tiene gran poder respecto a qué se elige como lectura.

Es ésta la que está en mejor posición para mostrarle al lector cómo Palacio, al desdoblarse, no sólo tergiversaba el statu quo literario, sino que también organizaba, subrepticia e inmediatamente, un proyecto acrático, una auto-estructura (o auto-proceso) que virtualmente englobaba todo aspecto de la literariedad del momento. Como texto cultural, la obra de Palacio es, en primer lugar, un modelo sintético que no resume totalmente el efecto de lo real que es natural para los portadores de la cultura en que se inscribe. Es decir, Un hombre muerto a puntapiés y textos subsecuentes son parte de una cultura dada que ya tenía en sí una serie de oposiciones semánticas que componen el lenguaje de la descripción del modelo.

Por esto es sorprendente que el artículo programático de una colección sobre la nueva novela ecuatoriana no haga mención de Palacio, y se diga que la narrativa ecuatoriana ingresa a cierto tipo de literariedad con un retraso de treinta años; es más, que "La novela ecuatoriana de las décadas del 40, 50 y 60 es de valor temático y en algunos casos estilístico [ $\dot{d}$ ?]; sin embargo, se siguen los mismo modelos técnicos y narrativos del realismo social del 30 '17. Esta impresión crítica, basada también en una bibliografía obsoleta sobre la novela hispanoamericana, es bastante sorprendente, debido a que én el mismo libro su autor, además de mencionar Entre Marx y una mujer desnuda, examina novelas como La Linares y Polvo y ceniza. Estas tres simplemente no ocasionaron un cambio milagroso para la narrativa ecuatoriana de los setenta.

Cuando en noviembre de 1978 se celebra el "Primer Encuentro sobre Literatura Ecuatoriana", lo que queda claro es que la desigual política cultural del país es en gran parte responsable por la recepción de autores como Palacio. El análisis textual de su obra

16 En Manuel Corrales Pascual (ed.), Situación del relato ecuatoriano. Cincuenta opiniones y una discusión, Universidad Católica, Quito, 1977, p. 323

17 ANTONIO SACOTO, "La novela ecuatoriana en el contexto de la latinoamericana", en La nueva novela ecuatoriana, Universidad, Cuenca (Ecuador), 1981 , p. 28. 
se agota y se convierte en repetitivo debido a la falta de preguntas. La historiografía literaria ecuatoriana (segunda de las situaciones que mencioné al principio), a pesar de los honestos esfuerzos de Hernán Rodríguez Castelo y Juan Valdano, mantiene los mismos problemas metodológicos que vienen afectando a todo historiador de la literatura hispanoamericana. Aunque la literatura es una de las manifestaciones culturales más desarrolladas en el Ecuador, "El problema básico del fenómeno cultural es la visión conceptual limitada, a veces únicamente subjetiva y sentimental, de la cultura y de su acción"'18.

En los países andinos como el Ecuador, el mestizaje nunca ha sido visto como una pluralidad real. Cuando se da un autor para quien ese mestizaje se da también en los géneros que practica -es decir, produciendo, digamos, novelas que no lo son en el sentido convencional-, la ofuscación genérica (la tercera de las situaciones que mencioné al principio) se convierte en ofuscación crítica. Se produce entonces un procedimiento reductor en el cual el concepto de literatura "ecuatoriana" alude sólo y exclusivamente a la literatura culta en español. Ante esta situación, la oralidad, tal como la practicaba Palacio en sus narraciones, es vista generalmente como la que se nota en las literaturas orales, en lenguas nativas. Por ende, es más difícil incluirla como parte representativa de la literatura nacional y caer en oposiciones ideológicas radicales ${ }^{19}$. Por esto:

El problema debe plantearse en otros términos, por cierto. En lo esencial, discutiendo el carácter imprescindible de la categoría de

18 DARIO MOREIRA, La política cultural en Ecuador, UNESCO, Paris, 1977, p. 76. Para mayores detalles consúltese HERNÁN RODRÍGUEZ CASTELO, 19691979: Diez años de cultura en el Ecuador, Publitécnica, Quito, 1980. Para esto, en relación a Palacio, véase DIEGO ARAUJO SÁNCHEZ, "Variaciones en torno a la novela ecuatoriana", en Luis Mora Ortega et al., Arte y cultura. Ecuador: 1830-1980, Corporación Editora Nacional, Quito, 1980, t. 2, pp. 299-325, en que retoma con variantes lo que manifiesta en su "Panorama de la novela ecuatoriana de los últimos años", Cultura, Quito, 1979, núm. 3, 17-25. Este número monográfico recoge las ponencias presentadas en el "Primer Encuentro sobre Literatura Ecuatoriana" mencionado anteriormente. Respecto al género novela, las ponencias publicadas contienen aserciones previsibles sobre Palacio.

${ }^{19}$ Examino más detalladamente estos problemas para la novela hispanoamericana en "Diez problemas para el novelista latinoamericano y la cultura crítica nacional"', TC, 1985, núms. 31/32, 271-297. Para el rnestizaje como referente empírico de la narrativa ecuatoriana véase RONALD STUTZMAN, "El mestizaje: An All-Inclusive Ideology", en Norman E. Whitten, Jr. (ed.), Cultural Transformations and Ethnicity in Modern Ecuador, University of Illinois Press, Urbana, 1981, pp. 45-94. 
unidad, que como se habrá comprendido es casi sinónimo de parcialidad y fragmentación, y postulando la opción de encarar objetos definidos por su multiplicidad heterogénea. En este sentido la crítica literaria latinoamericana tendría que habituarse a trabajar, en consonancia con su materia, sobre objetos internamente contradictorios. No está de más recordar que para ello existe el método dialéctico ${ }^{20}$.

Será entonces en los años ochenta cuando la narrativa de Palacio reciba un tratamiento más adecuado ${ }^{21}$. De esto surge la modernidad incierta (cuarta y última de las situaciones que mencioné) que rodea a Palacio. La parodia, que caracteriza mucho de las secuelas postmodernas del momento en que releemos a Palacio, en 1987, a cuarenta años de su muerte, es una práctica textual que el autor aplicó a la mayoría de lo que escribió. Es algo que, sin querer, todavía hacen algunos de sus críticos, sobre sí mismos.

Con la excepción del excelente análisis psicobiográfico de Renán Flores Jaramillo, en el que sintetiza de manera correctiva lo que se ha supuesto desordenadamente sobre la relación vida/obra en Palacio, una reciente floresta sobre este autor cae otra vez en

20 Antonio CoRnejo Polar, "Para una agenda problemática de la crítica literaria latinoamericana, diseño preliminar", en Sobre literatura y crítica latinoamericanas, Universidad Central de Venezuela, Caracas, 1982, p. 38. Después de la obra de Pedro Henríquez Ureña y los historiadores que he mencionado al principio, este tipo de revisionismo halla muchos ecos en años recientes. Para la especificidad ecuatoriana véase AGUSTín CUEva, "El método materialista histórico aplicado a la periodización de la historia de la literatura ecuatoriana: algunas consideraciones teóricas' , CasA, 1981, núm. 127, 31-48. Además de trabajos por Achugar, Goić, Mignolo, Navarro, Osorio Rincón y otros de Cornejo Polar en el libro citado, véanse ahora RAFAEL GUTIÉRREZ GIRARDOT, “El problema de una periodización de la historia literaria latinoamericana"' en Ana Pizarro (ed.), La literatura latinoamericana como proceso, C.E.A.L., Buenos Aires, 1985, pp. 119-131; BEATRIZ GonZÁlEz S., "Problems and Tasks of Latin American Historiography (The Continental and National Literary Histories)', Neoh, 1983, núm. 1, 275-298; LEO POLLMAN, "Hacia una periodización de la novela latinoamericana", HoGS, t. 2, pp. 695708; y los trabajos dedicados al tema en $N L H, 16$ (1985).

21 Dadas las limitaciones de espacio, sólo doy un registro de este tratamiento: WILFRIDO H. CORRAL, "Colindantes sociales y literarios de Débora de Pablo Palacio”', TC, 1979, núm. 14, 188-199; HernáN LAVÍN CERDA, "Pablo Palacio: el vértigo de la figura", CuA, 1984, núm. 6, 70-81; RENATO Prada Oropeza, “La metaliteratura de Pablo Palacio”, Hispam, 1981, núm. 28, 3-17; Alfredo PAREJA Diez-CANSEco, "El reino de la libertad en Pablo Palacio", CasA, 1981, núm. 127, 3-20; y ABDÓN UBIDIA, "Una luz lateral sobre Pablo Palacio", La Bufanda del Sol, 1974, núm. 8, pp. 9 y 11. 
la repetición, la ingenuidad, y poco añade a la renovación de sus lecturas $^{22}$. Palacio en verdad ha tenido suerte en ser considerado un maestro, sobre todo si se confirma que la preservación y renovación de maestros como él se ha convertido en el deber no de artistas y entusiastas, sino, como postula Frank Kermode, de cuidadosos catedráticos llenos de teoría y defensores del canon.

Para Kermode, "One of the factors ensuring the fallibility of system is the recognition that all observation is dependent upon theoretical presupposition; for such presupposition must vary from age to age, from one community of interpretation to another, and even from one individual to another"' ${ }_{23}$. Si vemos a Palacio y su obra desde esta perspectiva, notamos la necesidad de estudiar su recepción no sólo en términos de su relación con la narrativa hispanoamericana afín, sino en términos de su verdadera relación con la narrativa de su patria. Si decimos que "Palacio's sabotaging of the representation of reality, narrative self-consciousness, details bordering on the grotesque, and irony hold his readers', o que " $[\ldots]$ his subjective imagery [...] and transcription of psychic traumas make up a corpus characterized by existentialism, selfdeprecation, relegation of social criticism, and sophisticated technique, a combination subsequent narrative would emulate" ${ }^{24}$, esto debe ser dicho con clara conciencia de que Palacio crea un canon.

Este canon es el que la crítica establece como posterior al año 1930 , es la razón por la cual las aproximaciones a la narrativa ecuatoriana de este siglo se dan en un binarismo anterior y posterior a ese año. Miguel Donoso Pareja inteligentemente plantea que el devenir de todo corpus literario se da en espiral. Por esto, rupturas como la de Palacio se producen en las entrañas de una tradición, que la crítica no ha podido contextualizar. Decir que el realismo contra el que batallaba el autor es unidimensional es un lugar común que en las lecturas de hoy no conduce a nada.

${ }^{22}$ Me refiero a los trabajos recogidos en Cultura, Quito, 1984, núm. 20. De ellos, el más representativo de una postura acrítica, bombástica y sin mucha razón de ser en su anacrónico catálogo estilístico es el de Jaime Montesinos. No obstante, cabe dejar constancia de que el trabajo ya mencionado de Humberto Robles inicia una discusión de los primeros cuentos de Palacio que hasta la fecha no ha sido continuada.

${ }^{23}$ FRANK KERMODE, Forms of Attention, University of Chicago Press, Chicago, 1985, p. 82. Cf. Canons, ed. Robert von Hallberg, University of Chicago Press, Chicago, 1984.

${ }^{24}$ WILl H. CORRAL, "Ecuador", en David W. Foster (ed.), Handbook of Latin American Literature, Garland Publishing, New York-London, 1987, p. 281 . 
Cuando Donoso Pareja dice: "Palacio maneja ya la idea del deseo como motor de la organización del discurso [...] la escritura (aunque sea a gatas) se irá dando en el deseo y por él [...] quedarse en la simple historia es no haber leído nada" ${ }^{25}$, se está ante la lectura que va a producir una mira por la cual otros lectores llegarán a mayores logros interpretativos.

Otra vez, Jorge Enrique Adoum da el continuo crítico que debe ser la norma para la recepción de un autor como el que leemos. Correctamente, Adoum cree extraño que Palacio se haya declarado anti-realista con su primera obra, antes de que el realismo proliferara en la narrativa hispanoamericana, y antes de que apareciera en el Ecuador. En su excelente revisión de la crítica sobre Palacio, Adoum presenta la exégesis de que ninguno de los comentaristas de Palacio, actuando individualmente, "se dio cuenta de que al encontrarle entre todos semejanzas con unos quince autores diferentes, casi casi le estaban negando la originalidad que en él exaltaban ante el desconcierto de encontrarse por primera vez en nuestro país, y en aquella época, con una literatura que se piensa a sí misma..." 26

Por estas razones es más gratificante leer los estudios que se han hecho sobre Pablo Palacio. La fusión de voces narrativas que presenta no es solamente un recurso narratológico, sino que es en un sentido simbólico un proceso paralelo a las lecturas que se han hecho de su obra. Ésta, más que liberar al lector, lo aprisiona; más que hacerle sentirse ligado a un paradójico pasado y futuro vanguardista, le hace ver que tal solidaridad debe romperse en cuanto se establezca. Para desconcierto del lector, la provocación que ocasiona Palacio no cesa: se anulan héroes, desaparecen virtudes, posesiones, atributos, perfiles temporales y actuaciones; en lucha contra la artificiosidad y la solemnidad del discurso crítico que la quiere fijar.

WILFRIDO H. CORRAL

${ }^{25}$ Los grandes de la década del 30, El Conejo, Quito, 1985, p. 104.

26 "Prólogo" a PEDRO JORGE VERA (ed.), Narradores ecuatorianos del 30 , Biblioteca Ayacucho, Caracas, 1980, p. lvi. 